\title{
Clinical Course of Lung Cancer Patients with Subcutaneously Implanted Central Venous Access Device Ports from the Time of Receiving Chemotherapy to the Endpoint of Cancer
}

\author{
Tomonori Hirashima1*, Teppei Tsumori ${ }^{2,3}$, Kenichi Sakai ${ }^{4}$, Makoto Fujishima4, \\ Yukie Yamakawa', Noriko Ryouta', Masumi Sandoh', Takayuki Shiroyama1, \\ Motohiro Tamiya1, Naoko Morishita', Hidekazu Suzuki', Norio Okamoto', \\ Sho Goya ${ }^{2}$, Hironori Shigeoka ${ }^{4}$ \\ ${ }^{1}$ Departments of Thoracic Malignancy Osaka Prefectural Medical Center for Respiratory and \\ Allergic Diseases, Osaka, Japan \\ ${ }^{2}$ Departments of Palliative Medicine Osaka Prefectural Medical Center for Respiratory and \\ Allergic Diseases, Osaka, Japan \\ ${ }^{3}$ Tsumori Clinic, Osaka, Japan \\ ${ }^{4}$ Departments of Gastroenterological and Breast Surgery Osaka Prefectural Medical Center \\ for Respiratory and Allergic Diseases, Osaka, Japan \\ ${ }^{5}$ Departments of Nursing Osaka Prefectural Medical Center for Respiratory and Allergic Diseases, Osaka, Japan \\ ${ }^{6}$ Departments of Pharmacy Osaka Prefectural Medical Center for Respiratory and \\ Allergic Diseases, Osaka, Japan \\ Email: "hirashimat@ra.opho.jp
}

Received 7 June 2016; accepted 10 July 2016; published 13 July 2016

Copyright (C) 2016 by authors and Scientific Research Publishing Inc.

This work is licensed under the Creative Commons Attribution International License (CC BY).

http://creativecommons.org/licenses/by/4.0/

(c) (7) Open Access

\section{Abstract}

Background: As the prognosis of lung cancer (LC) patients improves, subcutaneously implanted central venous access device ports (CV-ports) have frequently been used for continuing chemotherapy (CC) or palliative care (PC). In this study, we examined the clinical course of LC patients with subcutaneously implanted CV-ports from the time of receiving chemotherapy to the endpoint of cancer. Materials and Methods: We retrospectively reviewed the clinical data and treatment history of LC patients with subcutaneously implanted CV-ports between June 2008 and November 2013 using clinical records and a pharmacy database. Results: Of the 132 LC patients with subcu"Corresponding author.

How to cite this paper: Hirashima, T., et al. (2016) Clinical Course of Lung Cancer Patients with Subcutaneously Implanted Central Venous Access Device Ports from the Time of Receiving Chemotherapy to the Endpoint of Cancer. Journal of Cancer Therapy, 7, 519-529. http://dx.doi.org/10.4236/jct.2016.77055 
taneously implanted CV-ports, 79 (59.8\%) had CV-ports for CC (the CC group) and $53(\mathbf{4 0 . 2 \% )}$ had CV-ports for PC (the PC group). After CV-port implantation, LC patients in the CC group received a median of two regimens with a median of 6 cycles. The median survival time of patients in the CC and PC groups was 457 and 44 days, respectively. In the CC group, the median survival time of small cell and non-small cell LC patients was 342 (95\% confidence interval, 235 - 627) and 563 (95\% confidence interval, 368 - 728$)$ days, respectively. Nine patients $(6.8 \%)$ had their CV-ports removed due to complications. Forty $(30.3 \%)$ of the 132 enrolled patients were referred for at-home PC. The at-home death rate observed among these 40 patients was $30.0 \%(N=12)$. Conclusion: CV-ports may contribute to seamless oncological care.

\section{Keywords}

\section{Clinical Course, At-Home Death Rate, Implanted Central Venous Access Device Port, Lung Cancer, Seamless Oncological Care}

\section{Introduction}

Lung cancer (LC) represents the leading cause of cancer-related deaths in men and the second leading cause of cancer-related deaths in women in 2008 [1]. However, two Japanese studies [2] [3] reported that the prognosis of advanced non-small cell LC (NSCLC) patients, especially those with an EGFR mutation-positive subtype, could be improved considerably by epidermal growth factor receptor-tyrosine kinase inhibitors with median overall survival rates of 27.7 and 34.3 months, respectively. We recently reported an increase in the number of NSCLC patients receiving long-term chemotherapy [4]. Among the 185 outpatients receiving chemotherapy in this study, the median total duration of chemotherapy was 287 (range 28 - 1815) days with 60 patients $(32.4 \%)$ receiving fourth-line chemotherapy [4]. Additionally, long-term survival (defined as $>5$ years) was observed not only in NSCLC patients with sensitive EGFR mutations, but also in NSCLC patients without sensitive EGFR mutations [5]. In this study, 22 patients survived $>5$ years, including 9 patients $(40.9 \%)$ with an $E G F R$ mutation, 8 patients (36.4\%) without, and 5 patients (22.7\%) with an unknown EGFR mutation status [5].

Since we frequently observe $\geq 100$ LC-related deaths each year at our institution, our team is required to manage various symptoms (e.g., delirium) in end-stage LC patients [6]. Thus, the proportion of LC patients in our care with subcutaneously implanted central venous access device ports (CV-ports) has been increasing. These CV-ports are used to secure an infusion route for continuing chemotherapy (CC) or for providing palliative care (PC) [7].

In patients with a variety of solid neoplastic diseases, outpatient chemotherapy is viable through the placement of a subcutaneously implanted CV-port and the use of a portable disposable pump [8] [9]. However, to the best of our knowledge, there have been no reports concerning the clinical course of LC patients with subcutaneously implanted CV-ports from the time of receiving chemotherapy to the endpoint of cancer.

Our previous study [6] demonstrated that the majority of patients at our institution have died during hospitalization. However, many terminally ill Japanese patients prefer to die at home [10], and in 2013, the at-home death rate of patients with malignant neoplasms was reported to be $9.5 \%$ [11]. Therefore, we have actively promoted collaboration with regional clinics as our medical regional alliances for at-home PC. This has resulted in an increase in the at-home death rate among LC patients receiving at-home PC [7]. Moreover, in a previous study of ours [7], the desire for an at-home death by both patients and caregivers was a strong predictor of the at-home death rate.

In the present study, we examined the clinical course of LC patients with subcutaneously implanted CV-ports from the time of receiving chemotherapy to the endpoint of cancer.

\section{Materials and Methods}

\subsection{Study Approval}

The study design was approved by the Institutional Review Board of the Osaka Prefectural Medical Center for 
Respiratory and Allergic Diseases (Osaka, Japan) on June 21, 2013 (Approval Number 643).

\subsection{Patient Selection and Categorization}

We retrospectively examined the medical records of patients who underwent subcutaneous CV-port implantation between June 1, 2008 and November 30, 2013 to secure an infusion route for CC in the CC group or for providing PC in the PC group.

\subsection{Clinical Review}

The clinical data of eligible patients were retrospectively reviewed. The eligibility criteria were as follows: 1) patients with histologically proven LC (small cell LC [SCLC] or NSCLC), 2) patients with subcutaneously implanted CV-ports, and 3) patients who received chemotherapy and/or PC at our institution. Patients with missing data concerning follow-up, chemotherapy regimens, and/or place of death were excluded.

Baseline demographic information including sex, age, histological subtype, Eastern Cooperative Oncology Group (ECOG) performance status (PS), and disease stage at the time of CV-port implantation was obtained for each patient. At the time of CV-port implantation, the following data were available for all patients: 1) complete medical history and physical examination findings, 2) surgical and pathological reports, 3) mediastinoscopy, fiberoptic bronchoscopy, and thoracoscopy findings, and 4) imaging investigation findings (chest radiography and computed tomography, brain computed tomography/magnetic resonance imaging, abdominal computed tomography, and bone scintigraphy/positron emission tomography).

\subsection{Central Venous Access Device Port Implantation and Maintenance}

CV-ports were implanted into LC patients by two surgeons. An indwelling catheter is normally inserted via the right subclavian vein on the lateral side under diagnostic ultrasonography guidance. If insertion via the right subclavian vein was considered difficult under ultrasonography guidance or on the basis of preoperative examination findings, the surgeons would attempt to insert the catheter via the left subclavian vein. Subsequently, catheter placement in the superior vena cava was confirmed using X-ray fluoroscopy imaging. If the surgeons experienced difficulty in positioning the catheter in the right or left subclavian vein, then the catheter would be placed in the right inguinal vein instead. The surgeons used a Groshong 8 F Single-Lumen CV Catheter and an M.R.I® Implantable Port (C. R. Bard, Inc., Summit, NJ, USA). CV-ports were punctured using a Huber-point needle for chemotherapy or for other purposes by a physician or nurse, respectively. The needle was flushed with saline and removed after infusion by a nurse or the patient's family doctor. Alternatively, the patients themselves could simply remove the needle. CV-ports were regularly flushed with saline at least every 4weeks even without intravenous infusion. The state of the catheter was regularly monitored using chest radiography obtained at a minimum interval of every 2 months. CV-ports were maintained until death or withdrawal due to complications or as per the patient's preferences.

\subsection{Chemotherapy}

The complete chemotherapy history of each patient was recorded, including the number of regimens and cycles, as well as the commencement and finish dates of each regimen. In this study, we included all anti-cancer regimens and cycles that were intravenously infused, but not those that were orally administered (e.g., epidermal growth factor receptor-tyrosine kinase inhibitors and S-1).

\subsection{Survival}

The survival time was defined as the interval (in days) between the date of CV-port implantation and the date of death or last follow-up. Survival data were last updated on November 3, 2014.

\subsection{Regional Medical Alliances and the Implementation of At-Home Clinics}

Our institution has been collaborating with 56 regional medical clinics for supportive/palliative care. Our institution's Regional Medical Liaison Office routinely refers appropriate at-home clinics to patients in need of such support. The majority of patients who accept a referral to a regional medical clinic receive at-home care. Consequently, some patients will die at home. 


\subsection{At-Home Death Rate}

In this study, the at-home death rate was defined as the ratio of at-home deaths to the total number of deaths. In addition, we calculated the at-home death rate of patients in the PC group.

\subsection{Statistical Analysis}

The overall survival rates were estimated using the Kaplan-Meier method [12]. Patient background data were compared using chi-square and Fisher's exact tests for categorical variables. Patient treatment data were compared using Mann- Whitney U tests. All statistical analyses were conducted using the statistical software package R (R Development Core Team. R: A Language and Environment for Statistical Computing. Vienna, Austria. 2011; ISBN 3-90005-07-0, http://www.R-project.org/). All comparisons with a $p<0.05$ were considered statistically significant.

\section{Results}

\subsection{Patient Demographics}

CV-ports were implanted into 132LC patients, including 90 men $(68.2 \%)$ and 42 women $(31.8 \%)$ with a median age of 67 (range, $36-87$ ) years (Table 1). Thirty-five patients $(26.5 \%)$ were diagnosed with SCLC. There mainly 97 patients $(73.5 \%)$ were diagnosed with NSCLC. An ECOGPS of $0-1,2-3$, and 4 was recorded for 59 $(44.7 \%), 51(38.6 \%)$, and 22 patients $(16.7 \%)$, respectively. Five patients $(3.8 \%)$ had Stage I/II disease, 14 patients $(10.6 \%)$ had Stage III disease, and 113 patients $(85.6 \%)$ had Stage IV disease. Of the 132 enrolled patients, 79 (59.8\%) had their CV-ports implanted to secure vascular access for CC (the CC group), whereas 53 (40.2\%) had their CV-ports implanted for PC purposes (the PC group). The proportions of patients with SCLC and an ECOG PS of $0-1$ in the CC group were significantly higher compared to those in the PC group ( $p=$ 0.016 and $p<0.0001$, respectively). Conversely, the proportion of patients with an ECOG PS of 4 was found to be significantly higher in the PC group compared to the CC group $(p<0.0001)$.

\subsection{Chemotherapy before Central Venous Access Device Port Implantation}

Table 1 presents the number of regimens and cycles of chemotherapy provided to patients before CV-port implantation. The number of cycles in the CC group was significantly higher than that of the PC group $(p=0.006)$.

\subsection{Post-Implantation Chemotherapy in the Continuing Chemotherapy Group}

Table 2 summarizes the chemotherapy regimens provided to LC patients in the CC group after CV-port implantation. There were no significant differences in the number of regimens or cycles between SCLC and NSCLC patients. After CV-port implantation in the CC group, SCLC patients frequently received treatment with amrubicin and platinum plus etoposide. Conversely, NSCLC patients frequently received treatment with docetaxel, platinum plus third-generation agents, and bevacizumab/pemetrexed-containing regimens

\subsection{Overall Survival}

As shown in Figure 1(a), the median survival time (MST) was significantly longer in the CC group compared to the PC group (MST [95\% confidence interval]: 457 [342 - 627] days vs. 44 [31 - 66] days; $p<0.0001$ ). In the CC group, the MST was significantly longer in patients with NSCLC compared to patients with SCLC (MST [95\% confidence interval]: 563 [368 - 728] days vs. 342 [235 - 627] days; $p=0.008$ ) (Figure 1(b)). In the PC group, the MST was not significantly different between patients with NSCLC and patients with SCLC (MST [95\% confidence interval]: 44 [30 - 75] days $v s .50 .5$ [27-NA] days; $p=0.863)$ (Figure 1(c)).

\subsection{Complications Due to Central Venous Access Device Port Implantation}

Nine $(9.8 \%)$ of the 132 enrolled patients required withdrawal of their CV-ports owing to a suspected infection $(N=3)$, fibrin sheath formation $(N=3)$, both a suspected infection and fibrin sheath formation $(N=1)$, deep venous thrombosis $(N=1)$, or port-site skin damage $(N=1)$. The median duration from the first insertion to CVport withdrawal was 113(range, 23 - 343) days. Of these 9 patients, $6(66.7 \%)$ had their CV-ports re-inserted. None of the patients died from the CV-port placement procedure or CV-port related complications. 


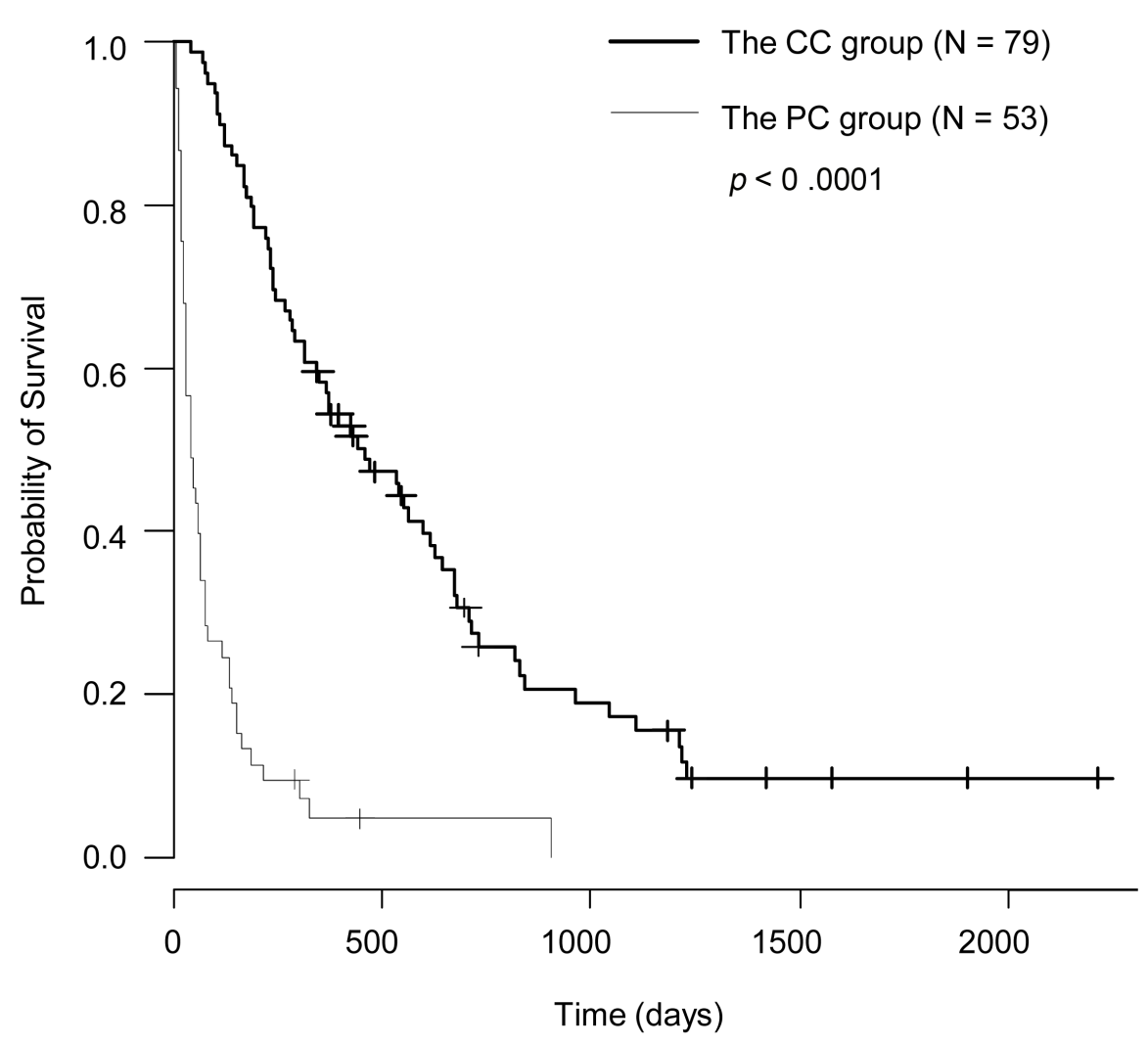

(a)

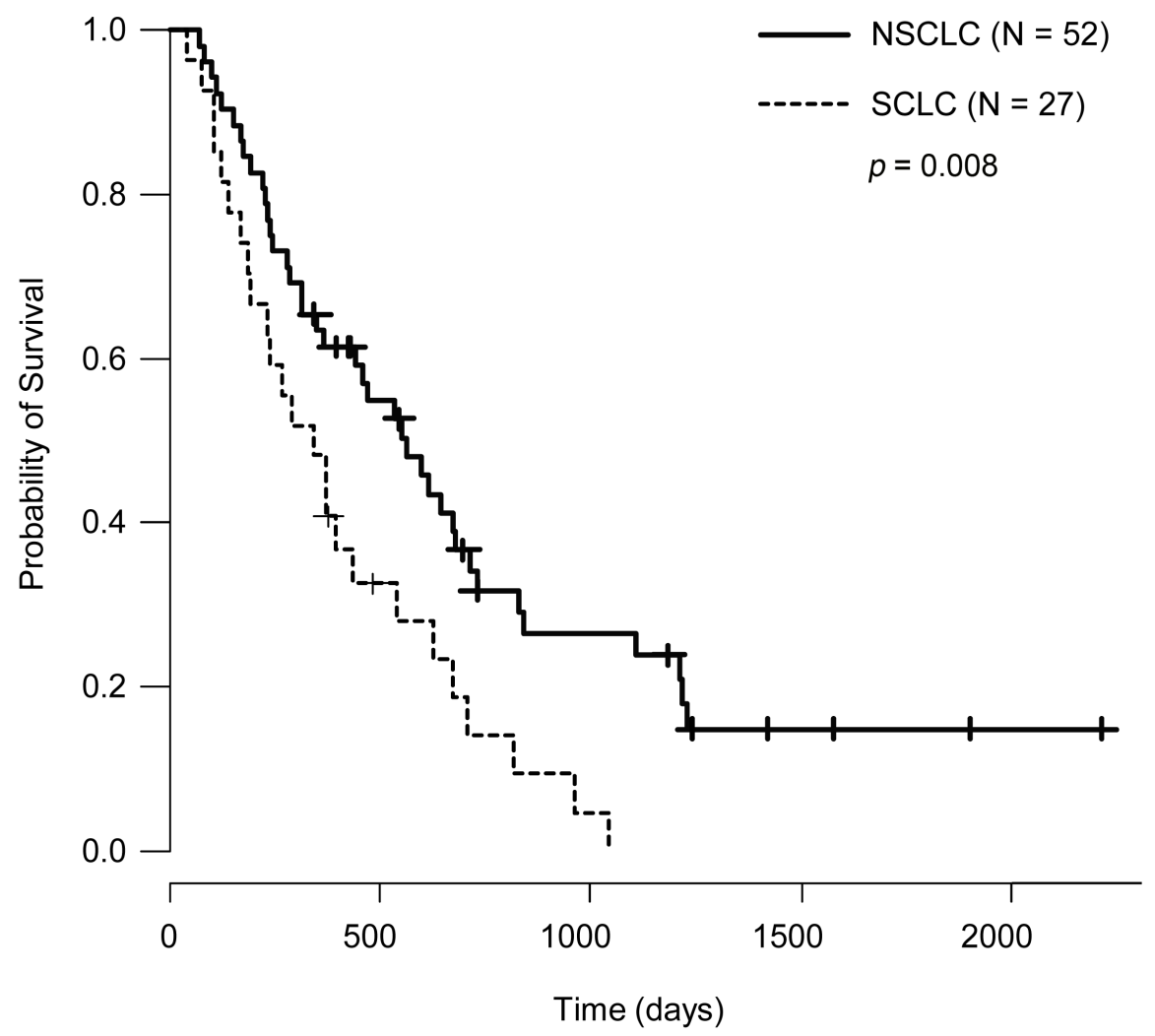

(b) 


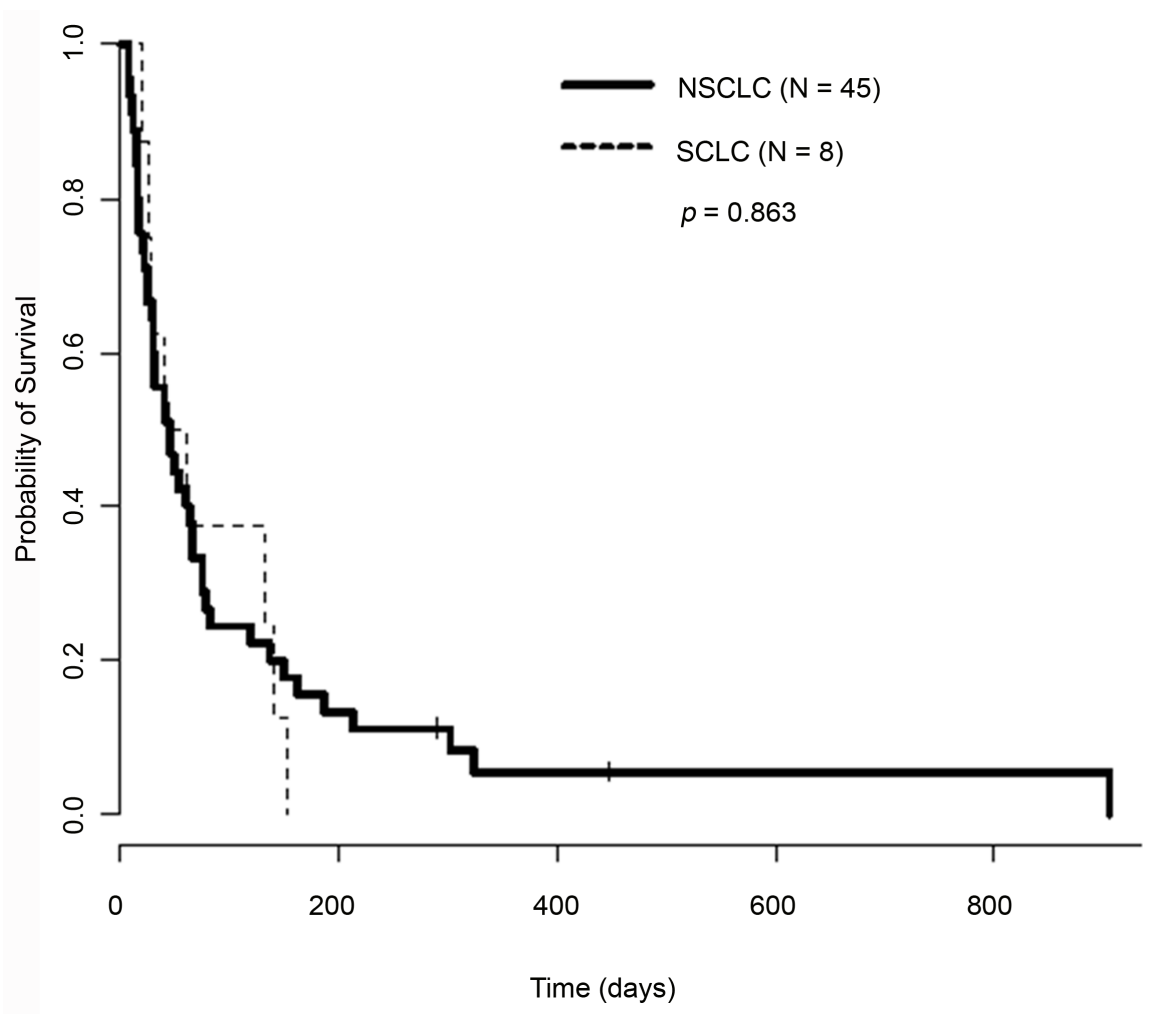

(c)

Figure 1. Kaplan-Meier survival curves of lung cancer patients $(N=132)$ with subcutaneously implanted central venous access device ports (CV-ports) according to (a) the purpose of $\mathrm{CV}$-port implantation and (b)-(c) histological subtype in the continuing chemotherapy $(\mathrm{CC} ; N=79)$ and palliative care $(\mathrm{PC} ; N=53)$ group. NSCLC, non-small cell lung cancer; SCLC, small cell lung cancer.

\subsection{Place of Death and At-Home Death}

As demonstrated in Table 3, 116(87.9\%) of the 132 enrolled patients died of LC, including 64 patients (81.0\%) in the $\mathrm{CC}$ group and 52 patients $(98.1 \%)$ in the PC group. Twelve (10.3\%) of the 116 deaths occurred at home, including 6 deaths $(9.4 \%)$ in the CC group and a further 6 deaths $(11.5 \%)$ in the PC group. The remaining 104 patients $(89.7 \%)$ died in hospital. Forty (30.3\%) of the 132 enrolled patients were referred by the Office of Regional Medical Alliances for at-home PC. The at-home death rate among these 40 patients was $30.0 \%(N=12)$. The death rates among patients referred for at-home PC were identical $(30.0 \%)$ in the $\mathrm{CC}$ and $\mathrm{PC}$ groups.

\section{Discussion}

In this study, we examined the clinical course of LC patients with subcutaneously implanted CV-ports from the time of receiving chemotherapy to the endpoint of cancer. In the CC group, SCLC and NSCLC patients continued to receive relatively long-term chemotherapy and achieved long-term survival after CV-port implantation. Our previous study [4] retrospectively demonstrated that long-term chemotherapy could prolong survival in advanced NSCLC patients who responded to first-line chemotherapy. Moreover, a recent study [13] prospectively demonstrated that pemetrexed continuation maintenance therapy was well-tolerated and offered superior overall survival rates compared toa placebo, further demonstrating that it was an efficacious treatment strategy for patients with advanced non-squamous NSCLC and a good ECOG PS who did not show progression during pemetrexed-cisplatin induction chemotherapy. Furthermore, the use of carboplatin and paclitaxel plus bevacizumab as a maintenance therapy was found to significantly prolong survival in non-squamous NSCLC patients compared to carboplatin and paclitaxel alone [14]. This finding was confirmed in a Chinese trial [15]. Therefore, as maintenance therapy with pemetrexed or bevacizumab could be a standard regimen for selected patients, techniques for administering maintenance therapy are needed and subcutaneously implanted CV-ports could be a very use- 
Table 1. Patient demographics $(N=132)$ at the implantation of subcutaneous central venous access device ports.

\begin{tabular}{|c|c|c|c|c|}
\hline \multirow{2}{*}{ Characteristics } & \multirow{2}{*}{$\begin{array}{l}\text { Patients } \\
(N=132)\end{array}$} & \multicolumn{2}{|c|}{ Purpose of CV-port implantation } & \multirow{2}{*}{$p$-value } \\
\hline & & CC group $(N=79)$ & PC group $(N=53)$ & \\
\hline \multicolumn{5}{|l|}{$\operatorname{Sex}, N(\%)$} \\
\hline Male & 90 & $53(58.9)$ & $37(41.1)$ & \\
\hline Female & 42 & $26(61.9)$ & $16(38.1)$ & 0.849 \\
\hline \multicolumn{5}{|l|}{ Age (years) } \\
\hline Median (range) & $67(36-87)$ & $66(36-85)$ & $67.5(42-87)$ & 0.232 \\
\hline \multicolumn{5}{|l|}{ Histology, $N(\%)$} \\
\hline SCLC & 35 & $27(77.1)$ & $8(22.9)$ & \\
\hline NSCLC & 97 & $52(53.6)$ & $45(46.4)$ & 0.016 \\
\hline \multicolumn{5}{|l|}{ ECOG PS, $N(\%)$} \\
\hline $0-1$ & 59 & $58(98.3)$ & $1(1.7)$ & \\
\hline $2-3$ & 51 & $20(39.2)$ & $31(60.8)$ & \\
\hline 4 & 22 & $1(4.5)$ & $21(95.5)$ & $<0.0001$ \\
\hline \multicolumn{5}{|l|}{ Stage, $N(\%)$} \\
\hline I-II & 5 & $4(80.0)$ & $1(20.0)$ & \\
\hline IIIA-B & 14 & $11(78.6)$ & $3(21.4)$ & \\
\hline IV & 113 & $64(56.6)$ & $49(43.4)$ & 0.243 \\
\hline \multicolumn{5}{|l|}{ Insertion site of the $\mathrm{CV}$-port, $N(\%)$} \\
\hline RSV & 91 & $60(65.9)$ & $31(34.1)$ & \\
\hline LSV & 23 & $13(56.5)$ & $10(43.5)$ & \\
\hline RIV & 16 & $5(31.3)$ & $11(68.7)$ & \\
\hline LIV & 1 & $0(0.0)$ & $1(100.0)$ & \\
\hline RIJV & 1 & $1(100.0)$ & $0(0.0)$ & \\
\hline \multicolumn{5}{|l|}{ Preimplantation chemotherapy } \\
\hline Number of regimens, median (range) & $2(0-7)$ & $2(0-7)$ & $2(0-6)$ & 0.060 \\
\hline Number of cycles, median (range) & $5(0-65)$ & $8(0-65)$ & $4(0-25)$ & 0.006 \\
\hline
\end{tabular}

CC, continuing chemotherapy; CV-port, central venous access device port; ECOG, Eastern Cooperative Oncology Group; LIV, left inguinal vein; LSV, left subclavian vein; NSCLC, non-small cell lung cancer; PC, palliative care; PS, performance status; RIJV, right internal jugular vein; RIV, right inguinal vein; RSV, right subclavian vein; SCLC, small cell lung cancer.

Table 2. Post implantation chemotherapy regimens and cycles in the continuing chemotherapy group $(N=79)$ according to histology.

\begin{tabular}{cccc}
\hline Histology & $\begin{array}{c}\text { Patients } \\
(\boldsymbol{N}=\mathbf{7 9})\end{array}$ & $\begin{array}{c}\text { Number of regimens, } \\
\text { median (range) }\end{array}$ & $\begin{array}{c}\text { Number of cycles, } \\
\text { median (range) }\end{array}$ \\
\hline All histological subtypes & 79 & $2(0-6)$ & $6(0-87)$ \\
SCLC & 27 & $2(1-3)$ & $4(1-20)$ \\
NSCLC & 52 & $2(0-6)$ & $7(0-87)$ \\
\hline
\end{tabular}




\begin{tabular}{|c|c|c|c|}
\hline \multicolumn{4}{|l|}{ Continued } \\
\hline Amrubicin & 15 & - & $3(1-14)$ \\
\hline Platinum + etoposide & 14 & - & $2(1-16)$ \\
\hline Irinotecan & 8 & - & $1.5(1-13)$ \\
\hline Nogitecan & 6 & - & $1.5(1-4)$ \\
\hline Other drugs & 3 & - & $2(1-3)$ \\
\hline \multicolumn{4}{|l|}{ NSCLC regimens } \\
\hline Docetaxel & 17 & - & $2(1-59)$ \\
\hline Pemetrexed & 15 & - & $3(1-23)$ \\
\hline Platinum + third - generation drugs & 10 & - & $3(1-6)$ \\
\hline Platinum doublet + bevacizumab & 10 & - & $3.5(1-7)$ \\
\hline Pemetrexed + bevacizumab & 9 & - & $6(1-15)$ \\
\hline Bevacizumab & 8 & - & $4(2-16)$ \\
\hline Gemcitabine & 7 & - & $3(1-9)$ \\
\hline Vinorelbine & 7 & - & $3(1-10)$ \\
\hline Irinotecan & 6 & - & $3.5(1-21)$ \\
\hline Platinum + pemetrexed & 5 & - & $1(1-5)$ \\
\hline Other drugs & 9 & - & $3(1-19)$ \\
\hline
\end{tabular}

NSCLC, non-small cell lung cancer; SCLC, small cell lung cancer.

Table 3. Differences in the prevalence of at-home palliative care, Prognosis, and Place of Death According to the purpose of subcutaneously implanted central venous access device ports.

\begin{tabular}{|c|c|c|c|c|}
\hline & & Overall & $\mathrm{CC}$ group & PC group \\
\hline \multirow[t]{2}{*}{ Prognosis $(\%)$} & Censored case & $16(12.1)$ & $15(19.0)$ & $1(1.9)$ \\
\hline & Fatal case & $116(87.9)$ & $64(81.0)$ & $52(98.1)$ \\
\hline \multirow[t]{2}{*}{ Place of death (\%) } & Hospital & $104(89.7)$ & $58(90.6)$ & $46(88.5)$ \\
\hline & Home & $12(10.3)$ & $6(9.4)$ & $6(11.5)$ \\
\hline \multirow[t]{2}{*}{ At-home palliative care $(\%)$} & No & $92(69.7)$ & $59(74.7)$ & $33(62.3)$ \\
\hline & Yes $^{a}$ & $40(30.3)$ & $20(25.3)$ & $20(37.7)$ \\
\hline At-home death $(\%)$ & & $6(30.0)$ & $6(30.0)$ & $6(30.0)$ \\
\hline
\end{tabular}

aAll patients had died. Abbreviations: Censored case, living or lost to follow-up; CV-port: subcutaneously implanted central venous access device port; $\mathrm{CC}$ group, patients who hadCV-port implantation for continuing chemotherapy; PC group, patients who had CV-port implantation for palliative care purposes.

ful device for such a purpose. Conversely, most SCLC patients in Japan receive amrubicin as a second or thirdline chemotherapy. Our previous study [16] retrospectively demonstrated that a proportion of patients treated with amrubicin received long-term treatment. Because amrubicin can occasionally cause severe vasculitis, most physicians have concerns regarding vascular leaking or difficulty in securing an infusion route. Thus, the SCLC patients in our study had CV-ports implanted to secure an infusion route before, on commencement of, or after amrubicin treatment. In our study, patients with SCLC or NSCLC had similar or longer survival times than those 
patients receiving second-line chemotherapy in previous studies [17] [18]. However, in the PC group, the MST was only 44 days after CV-port implantation. Thus, CV-port implantation for PC should be performed after a more careful patient selection process than that described in the present study.

The frequency of complications associated with CV-port implantation in the subclavian or inguinal veins was $6.8 \%$ with major complications including a suspected infection and fibrin sheath formation. Diagnostic ultrasonography guidance prevented pneumothorax and artery puncture during the CV-port placement procedure. Recently, Shiono et al. [9] reported that the complication rates associated with CV-port implantation in the subclavian vein and upper arm were $10.2 \%$ and $4.7 \%$, respectively. Therefore, it was concluded that upper arm implantation might be better, while considering patient safety and comfort. However, in the present study, a complication rate of $6.8 \%$ was lower than that of the subclavian group, but higher than that of the upper arm group [9]. Therefore, we should consider the upper arm as an alternative insertion site. Since LC is strongly associated with thromboembolic events in patients with subcutaneously implanted CV-ports [19], the insertion site of the CV-port should be carefully selected for LC patients.

The at-home death rate (10.3\%) in this study was similar to the previously reported $9.5 \%$ in cancer patients in Japan [11]. However, cancer patients who die in hospitals or intensive care units are frequently associated with a lower quality of life compared to those cancer patients who die at home [20]. In Japan, the majority of cancer patients prefer to die at home rather than in hospital [21]. The at-home death rate in Japan is lower than that of other developed countries [22]. In this study, 40(30.3\%) of the 132 enrolled patients were referred for at-home PC through regional medical alliances and among them, 30.0\% died at home $(N=12)$. This finding suggests that $\mathrm{CV}$-port implantation may lead to an increase in the number of patients receiving at-home PC. As a result, patients and caregivers may come to prefer an at-home death rather than a hospital death. Securing an infusion route through CV-port implantation may be useful not only for CC, but also for various PC purposes. The limitations of this study include its single center, retrospective design and the absence of control patients without subcutaneously implanted CV-ports. Therefore, it remains to be determined whether CV-port implantation is effective for oncological care. However, our findings are supportive of the conclusion of Shoino et al. [9] that subcutaneously implanted CV-ports may be used for multiple purposes and could contribute to secure, safe, and seamless oncological care from the time of receiving chemotherapy to at-home PC.

\section{Conclusion}

To the best of our knowledge, this study is the first to examine the clinical course of LC patients with subcutaneously implanted CV-ports from the time of receiving chemotherapy to the endpoint of cancer with the cooperation of medical regional alliances. Subcutaneously implanted CV-ports may contribute to seamless oncological care from the time of receiving chemotherapy to at-home PC. To confirm our findings, we will compare the quality of life of LC patients before and after CV-port implantation.

\section{Acknowledgements}

We would like to thank Editage (www.editage.jp) for English language editing.

\section{Funding}

This study was funded by the Osaka Medical Research Foundation for Intractable Diseases (13-2-27).

\section{Conflict of Interest}

TH has received research grants from Chugai Pharmaceutical Co., Ltd. (Tokyo, Japan), Taiho Pharmaceutical Co., Ltd. (Tokyo, Japan), Ono Pharmaceutical Co., Ltd. (Osaka, Japan), Kyowa Hakko Kirin Co., Ltd. (Tokyo, Japan), Astra Zeneca (Osaka, Japan), Eli Lilly Japan K.K. (Hyogo, Japan), MSD K.K. (Tokyo, Japan), and Merck Serono Co., Ltd. (Tokyo, Japan). All other authors have no conflict of interest.

\section{References}

[1] Jemal, A., Bray, F., Center, M.M., Ferlay, J., Ward, E. and Forman, D. (2011) Global Cancer Statistics. CA: A Cancer Journal for Clinicians, 61, 69- 90. http://dx.doi.org/10.3322/caac.20107 
[2] Mitsudomi, T., Morita, S., Yatabe, Y., et al. (2012) Updated Overall Survival Results of WJTOG 3405, a Randomized Phase III Trial Comparing Gefitinib (G) with Cisplatin Plus Docetaxel (CD) as the First-Line Treatment for Patients with Non-Small Cell Lung Cancer Harboring Mutations of the Epidermal Growth Factor Receptor (EGFR). Journal of Clinical Oncology, 30, 7521.

[3] Inoue, A., Kobayashi, K., Maemondo, M., et al. (2013) Updated Overall Survival Results from a Randomized Phase III Trial Comparing Gefitinib with Carboplatin-Paclitaxel for Chemo-Naïve Non-Small Cell Lung Cancer with Sensitive EGFR Gene Mutations (NEJ002). Annals of Oncology, 24, 54-59. http://dx.doi.org/10.1093/annonc/mds214

[4] Hirashima, T., Suzuki, H., Kobayashi, M., et al. (2012) Long-Term Chemotherapy May Prolong Survival in Advanced Non-Small-Cell Lung Cancer Among Responders to First-Line Chemotherapy. Medical Oncology, 29, 1629-1637. http://dx.doi.org/10.1007/s12032-011-0034-6

[5] Hirashima, T., Suzuki, H., Okamoto, N., Morishita, N., Yamadori, T., Tamiya, M., Shiroyama, T., Kurata, K. and Kawase, I. (2014) Important Factors for Achieving Survival of Five Years or More in Non-Small Cell Lung Cancer Patients with Distant Metastasis. Oncology Letters, 8, 327-334. http://dx.doi.org/10.3892/ol.2014.2107

[6] Suzuki, H., Hirashima, T., Kobayashi, M., et al. (2013) Impact of Pneumonia on Hyperactive Delirium in End-Stage Lung Cancer Patients. Support Care Cancer, 21, 281-285. http://dx.doi.org/10.1007/s00520-012-1522-8

[7] Higashiguchi, M., Hirashima, T., Goya, S., et al. (2012) Predictors of Home Deaths in Patients with Terminal Lung Cancer: A Single Center Retrospective Study. AJRS, 1, 458-463.

[8] Biffi, R., de Braud, F., Orsi, F., et al. (1998) Totally Implantable Central Venous Access Ports for Long-Term Chemotherapy. A Prospective Study Analyzing Complications and Costs of 333 Devices with a Minimum Follow-Up of 180 Days. Annals of Oncology, 9, 767-773. http://dx.doi.org/10.1023/A:1008392423469

[9] Shiono, M., Takahashi, S., Kakudo, Y., et al. (2014) Upper Arm Central Venous Port Implantation: A 6-Year Single Institutional Retrospective Analysis and Pictorial Essay of Procedures for Insertion. PLoS ONE, 9, e91335. http://dx.doi.org/10.1371/journal.pone.0091335

[10] Sanjo, M., Miyashita, M., Morita, T., Hirai, K., Kawa, M., Akechi, T. and Uchitomi, Y. (2007) Preferences Regarding End-of-Life Cancer Care and Associations with Good-Death Concepts: A Population-Based Survey in Japan. Annals of Oncology, 18, 1539-1547. http://dx.doi.org/10.1093/annonc/mdm199

[11] Ministry of Internal Affairs and Communications Bureau of Statistics (2011) e-Stat Portal Site of Official Statistics of Japan. http://e-stat.go.jp/SG1/estat/List.do?lid=000001108740.html

[12] Kaplan, E.L. and Meier, P. (1958) Nonparametric Estimation from Incomplete Observations. Journal of the American Statistical Association, 53, 457-481. http://dx.doi.org/10.1080/01621459.1958.10501452

[13] Paz-Ares, L., de Marinis, F., Dediu, M., et al. (2012) Maintenance Therapy with Pemetrexed Plus Best Supportive Care versus Placebo Plus Best Supportive Care after Induction Therapy with Pemetrexed Plus Cisplatin for Advanced Non-Squamous Non-Small-Cell Lung Cancer (PARAMOUNT): A Double-Blind, Phase 3, Randomised Controlled Trial. The Lancet Oncology, 13, 247-255. http://dx.doi.org/10.1016/S1470-2045(12)70063-3

[14] Sandler, A., Gray, R., Perry, M.C., et al. (2006) Paclitaxel-Carboplatin Alone or with Bevacizumabfor Non-Small-Cell Lung Cancer. The New England Journal of Medicine, 355, 2542-2550. http://dx.doi.org/10.1056/NEJMoa061884

[15] Zhou, C., Wu, Y.L., Chen, G., et al. (2015) BEYOND: A Randomized, Double-Blind, Placebo-Controlled, Multicenter, Phase III Study of First-Line Carboplatin/Paclitaxel Plus Bevacizumab or Placebo in Chinese Patients with Advanced or Recurrent Nonsquamous Non-Small-Cell Lung Cancer. Journal of Clinical Oncology, 19, 2197-2204. http://dx.doi.org/10.1200/JCO.2014.59.4424

[16] Higashiguchi, M., Suzuki, H., Hirashima, T., et al. (2012) Long-Term Amrubicin Chemotherapy for Small-Cell Lung Cancer. Anticancer Research, 32, 1423-1427.

[17] Murakami, H., Yamamoto, N., Shibata, T., et al. (2014) A Single-Arm Confirmatory Study of Amrubicin Therapy in Patients with Refractory Small-Cell Lung Cancer: Japan Clinical Oncology Group Study (JCOG0901). Lung Cancer, 84, 67-72. http://dx.doi.org/10.1016/j.lungcan.2014.01.012

[18] Kawaguchi, T., Ando, M., Asami, K., et al. (2014) Randomized Phase III Trial of Erlotinib versus Docetaxel as Second- or Third-Line Therapy in Patients with Advanced Non-Small-Cell Lung Cancer: Docetaxel and Erlotinib Lung Cancer Trial (DELTA). Journal of Clinical Oncology, 18, 1902-1908. http://dx.doi.org/10.1200/JCO.2013.52.4694

[19] Hohl Moinat, C., Périard, D., Grueber, A., Hayoz, D., Magnin, J.-L., André, P., Kung, M. and Betticher, D.C. (2014) Predictors of Venous Thromboembolic Events Associated with Central Venous Port Insertion in Cancer Patients. Journal of Oncology, 2014, Article ID: 743181. http://dx.doi.org/10.1155/2014/743181

[20] Wright, A.A., Keating, N.L., Balboni, T.A., et al. (2010) Place of Death: Correlations with Quality of Life of Patients with Cancer and Predictors of Bereaved Caregivers' Mental Health. Journal of Clinical Oncology, 28, 4457-4464. http://dx.doi.org/10.1200/JCO.2009.26.3863

[21] Fukui, S., Fujita, J., Tsujimura, M., Sumikawa, Y. and Hayashi, Y. (2011) Predictors of Home Death of Home Pallia- 
tive Cancer Care Patients: A Cross-Sectional Nationwide Survey. International Journal of Nursing Studies, 48, 1393 1400. http://dx.doi.org/10.1016/j.ijnurstu.2011.05.001

[22] Cohen, J., Houttekier, D., Onwuteaka-Philipsen, B., et al. (2010) Which Patients with Cancer Die at Home? A Study of Six European Countries Using Death Certificate Data. Journal of Clinical Oncology, 28, 2267-2273.

http://dx.doi.org/10.1200/JCO.2009.23.2850

\section{Submit or recommend next manuscript to SCIRP and we will provide best service for you:}

Accepting pre-submission inquiries through Email, Facebook, Linkedin, Twitter, etc A wide selection of journals (inclusive of 9 subjects, more than 200 journals)

Providing a 24-hour high-quality service

User-friendly online submission system

Fair and swift peer-review system

Efficient typesetting and proofreading procedure

Display of the result of downloads and visits, as well as the number of cited articles

Maximum dissemination of your research work

Submit your manuscript at: http://papersubmission.scirp.org/ 